\title{
MODULE
}

\section{The Basics: Gender Equality}

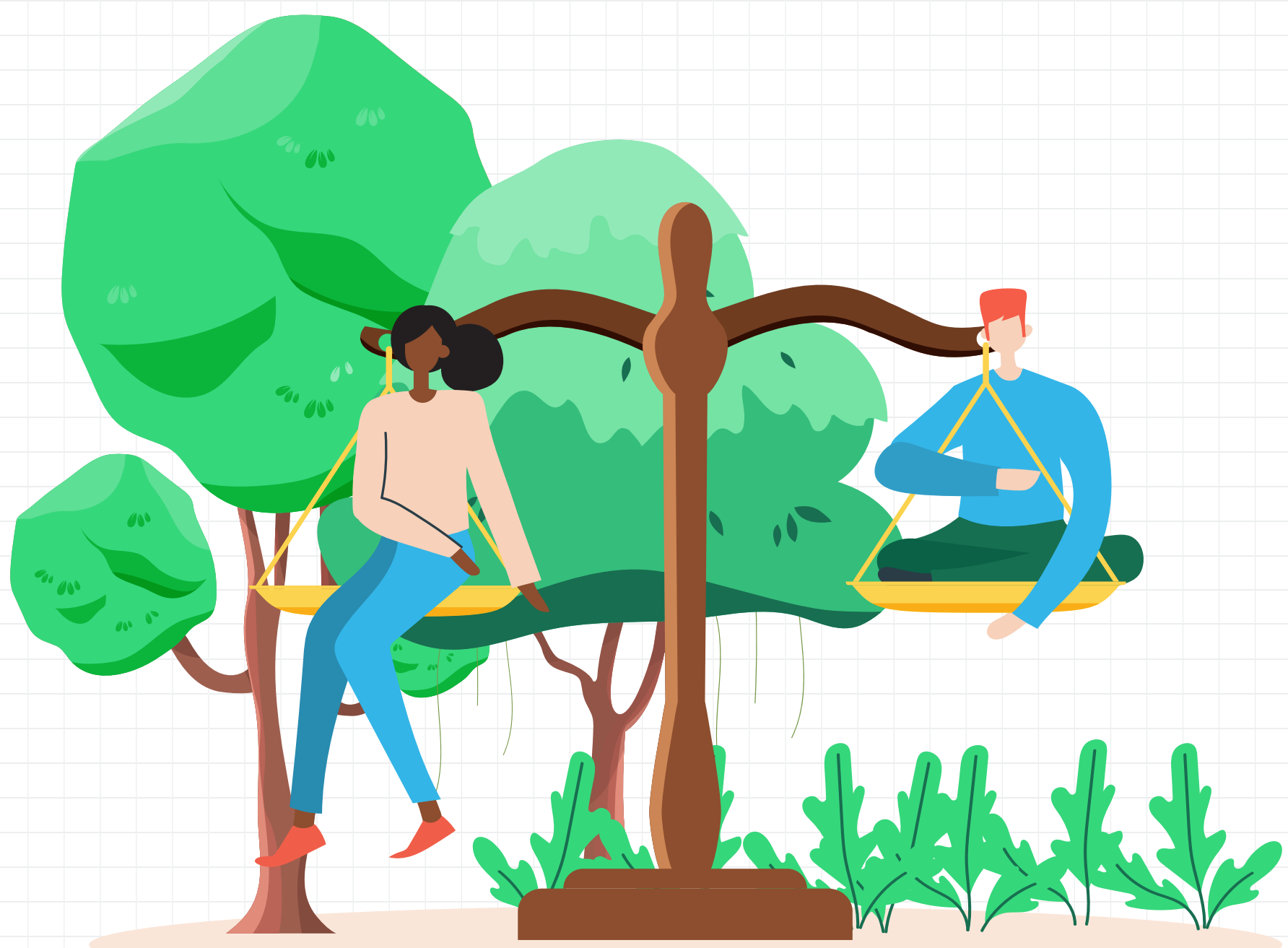

RESEARCH PROGRAM ON

Forests, Trees and Agroforestry

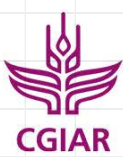

GENDER Platform 


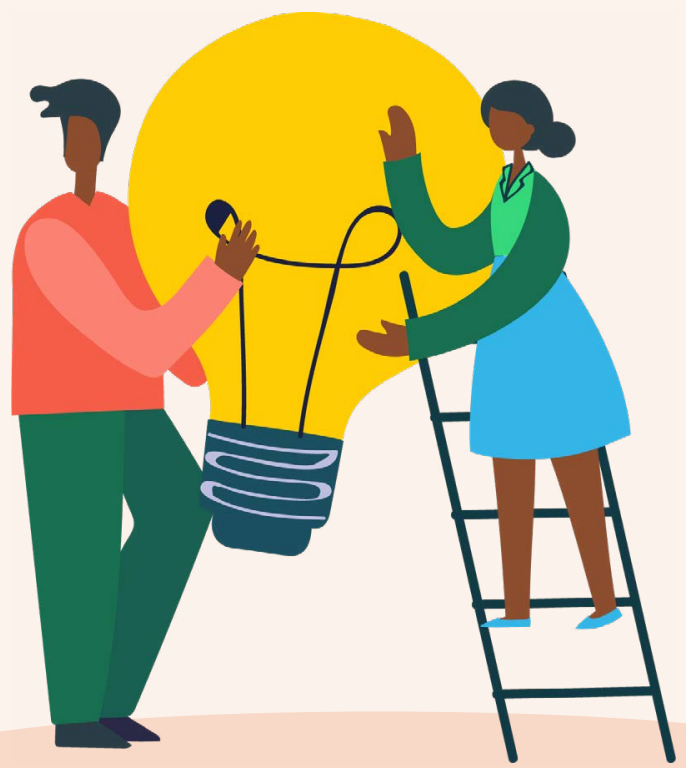

\section{Citation}

CGIAR Research Program on Forests, Trees and Agroforestry. 2021. Module 1. The basics: Gender Equality. Gender and Inclusion in Forest Landscape Restoration.

Center for International Forestry Research (CIFOR), Bogor, Indonesia. https://doi.org/10.17528/cifor/008351

\section{Authors (listed alphabetically)}

Marlène Elias, Alliance of Bioversity International and CIAT Molly Gilligan, EnGen Collaborative Margaux Granat, EnGen Collaborative Markus Ihalainen, Center for International Forestry Research (CIFOR)

Iliana Monterroso, Center for International Forestry Research (CIFOR)

Ana Maria Paez Valencia, World Agroforestry

\section{Acknowledgements}

This guide was produced with the financial support of the CGIAR Research Program on Forests, Trees and Agroforestry; the CGIAR GENDER Platform; and the CGIAR Trust Fund Donors. The authors gratefully acknowledge Haley Zaremba and Fabio Ricci for their assistance. 


\section{About this guide}

This guide supports the Gender and Inclusion in Forest Landscape Restoration (FLR) e-learning course. The course aims to build the capacities and understanding of diverse stakeholders on the gender and FLR nexus and address inequalities for more equitable and sustainable FLR.
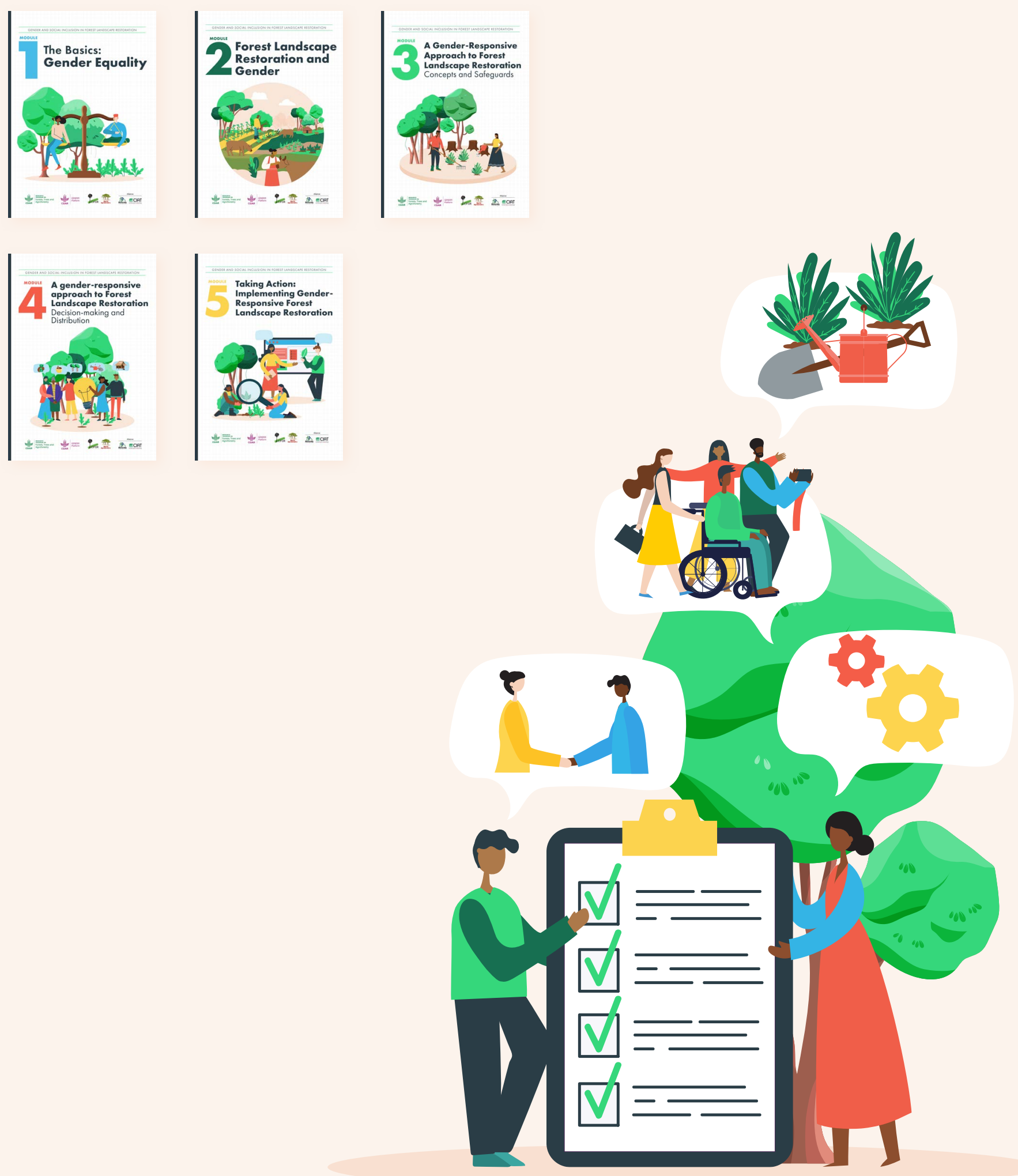


\section{Contents}

\section{PART 1: UNDERSTANDING KEY TERMS}

What is the difference between sex and gender?

Gender roles

Gender equality and equity

Intersectionality

PART 2: KEY CONCEPTS FOR ADVANCING GENDER EQUALITY

Gender mainstreaming

Stakeholder analysis

Enabling conditions for mainstreaming gender

Women's economic empowerment

Towards gender equality

Gender equity and equality frameworks

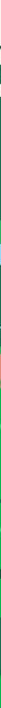




\section{PART ONE \\ Understanding key terms}

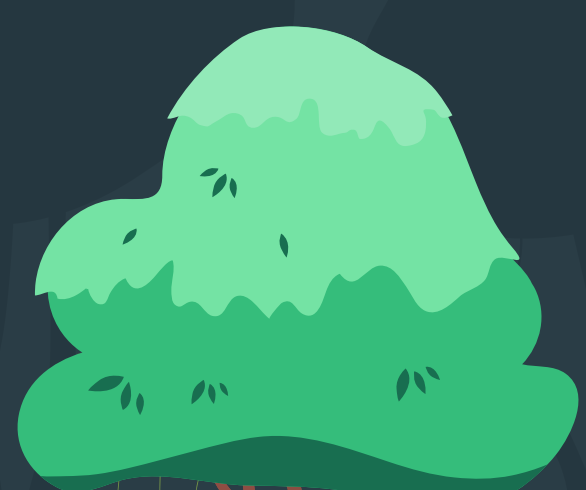

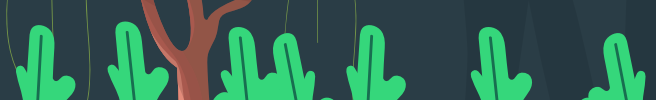

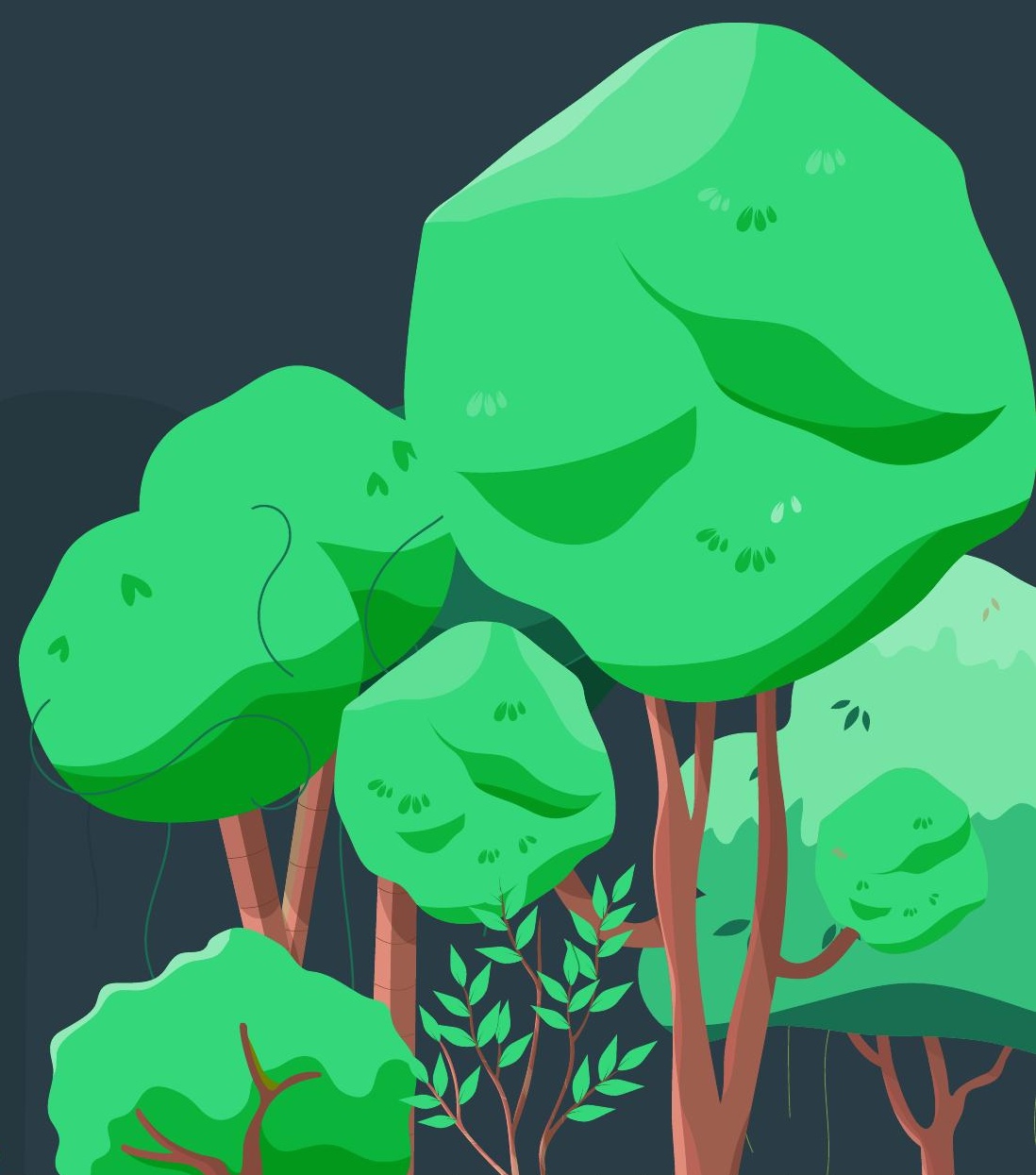




\section{What is the difference between sex and gender?}

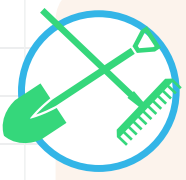

Gender involves how a person identifies and refers to the characteristics of women, men, girls and boys or other genders that are socially constructed. This includes norms, behaviours and roles associated with being, as well as relationships with each other. As a social construct, the norms, behaviours and roles associated with a certain gender vary from society to society and can change over time.'

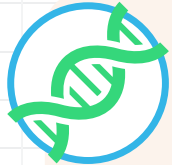

Sex refers to the physical differences between people who are male, female, or intersex. A person typically has their sex ascribed at birth based on physiological characteristics, including their genitalia and chromosome composition. This ascribed sex is called a person's 'natal sex'.

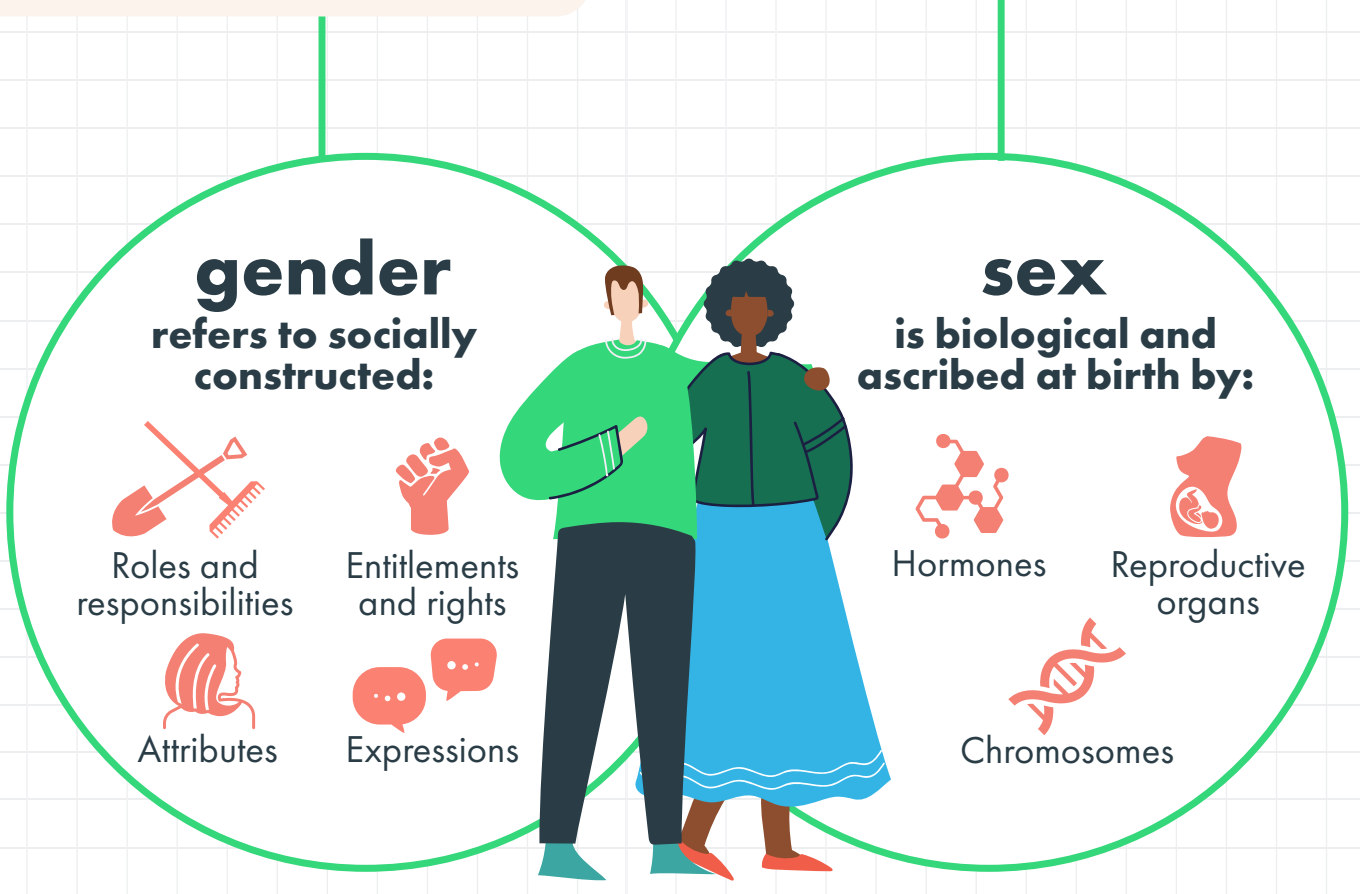

Non-binary/third gender refers to people whose gender identity falls outside the gender binary of man or woman. Throughout human history, cultures and societies around the globe have recognized diverse gender identities and expressions outside the binary of woman and man (sometimes collectively referred to as third gender). ${ }^{2}$ 


\section{Gender roles}

Gender roles refer to the behaviours, tasks and attitudes that a society considers appropriate for women and men. ${ }^{3}$

Women and men, as well as girls and boys, often perform different tasks and hold different responsibilities due to their socially-ascribed gender roles. This is a key factor in all aspects of family and community life, including with respect to how women and men interact with, rely upon and are responsible for their environment. Gender-differentiated roles and responsibilities affect women's and men's priorities and responsibilities when it comes to forest and landscape restoration (FLR) decisions and practices. ${ }^{3}$

Women's and men's tasks are often valued and rewarded differently by society. A clear example of this is the association of women with care and domestic work, which is typically unpaid and undervalued despite being essential for the household and for community well-being. ${ }^{4}$

Women's work in productive spaces (informal as well as formal) is often overlooked and underestimated. ${ }^{4}$ It is often considered as an extension of their household work and not valued as an essential contribution to the family, community and broader society.

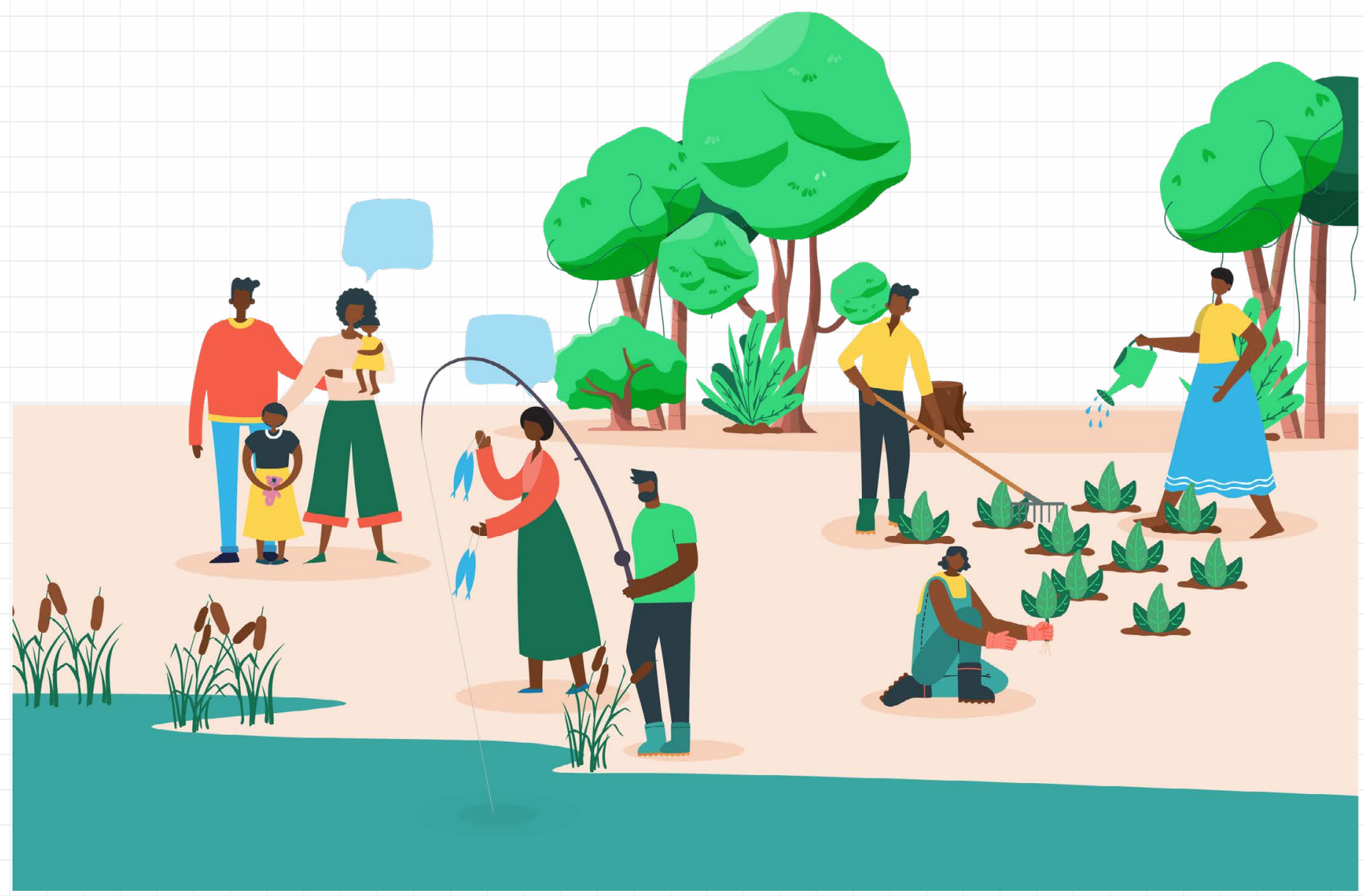

The gender-based division of labour and the value placed on women's and men's work has implications for:

- participation \& decision making, and

- entitlements \& rights. 


\section{Gender equality and equity}

Through a human rights lens, equality refers to the notion that every individual is entitled to the same rights, responsibilities and opportunities, and they should not be discriminated against.

\section{Gender equality means that the different} behaviours and aspirations of women and men are valued and considered equally. ${ }^{5}$ It does not mean that women and men have to become the same, but that their rights, responsibilities and opportunities will not depend on whether they are male or female.

Gender inequality is rooted in uneven power dynamics that give disproportionate power, resources and access to one group over another. Across contexts and geographies, women and sexual minorities experience social, cultural, legal and economic barriers that restrict their equal access to opportunities compared to men. Gender equality approaches often focus on addressing these barriers and empowering marginalised groups to shift power imbalances and open avenues towards equal opportunities for all. ${ }^{3}$

Gender equity is anchored in principles of justice. Gender equity promotes equality through recognising and addressing social structures that inhibit women and men from fully exercising and benefiting from their rights. It refers to the process of treating women and men fairly, according to their respective needs, which can include specific measures to compensate for historical and structural disadvantages. ${ }^{5}$

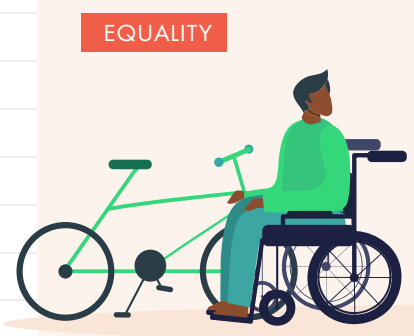

EQUITY

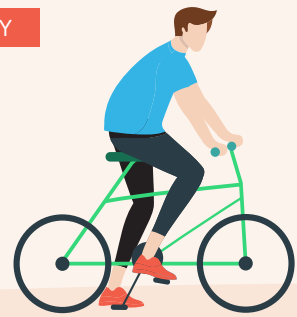

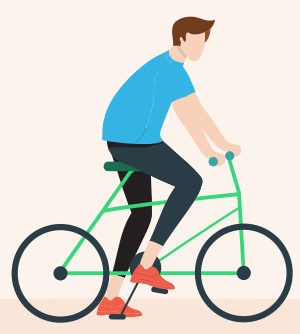
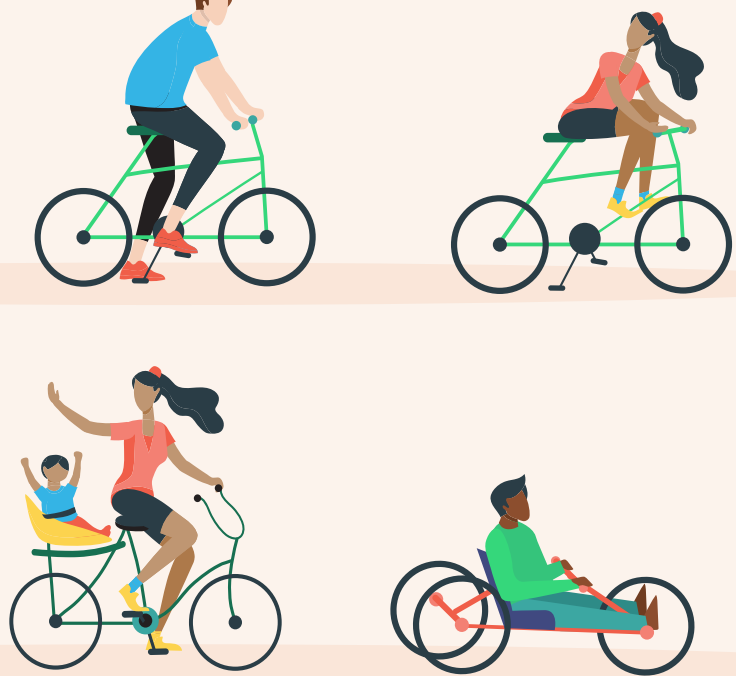

'Equality' in processes means giving the same support to all individuals, irrespective of their specific needs.
'Equity' in processes means providing different support to different individuals based on their needs, to reach a fair outcome.

Equitable and just processes need to be applied in pursuing equality, which is the state of all groups being equal in rights, status and opportunities. 


\section{Intersectionality}

Intersectionality is the concept that all oppression is linked. It is defined as the interconnected nature of social categorisations and identities such as age, ethnicity, gender, sexuality, indigeneity and class, that create interdependent systems of experience, discrimination and/or disadvantage. ${ }^{6}$

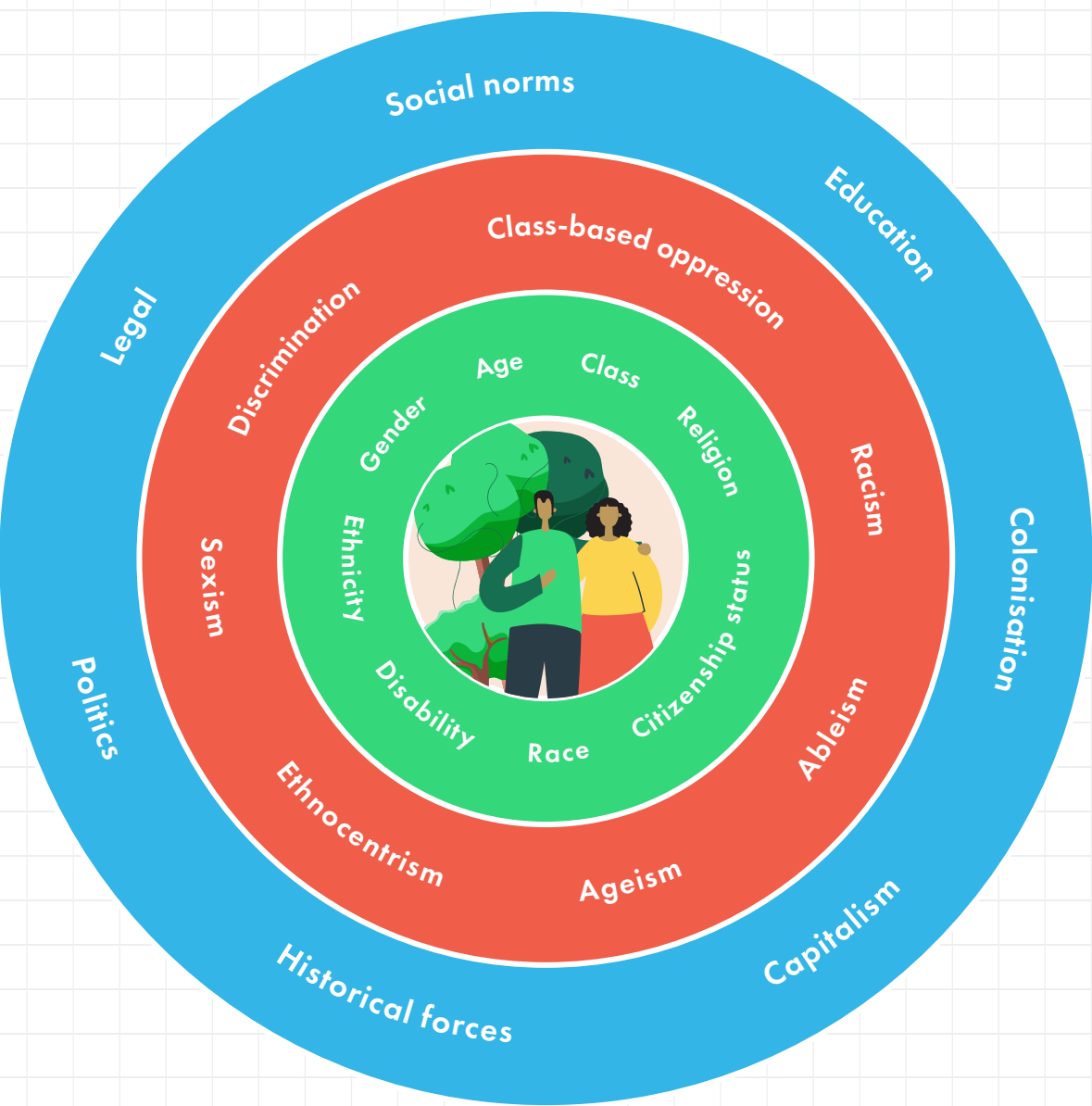

Unique circumstances and experiences
Aspects of identity
Types of discrimination impacting identity
Larger forces and structures reinforcing exclusion 
PART TWO

\section{Key concepts for advancing gender equalify}

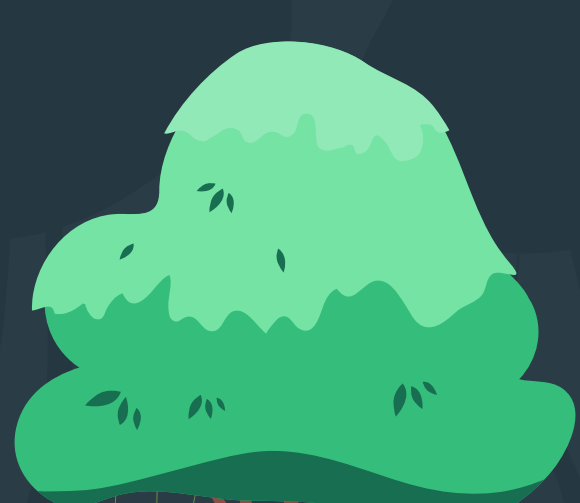

$n, n \in M n \in$

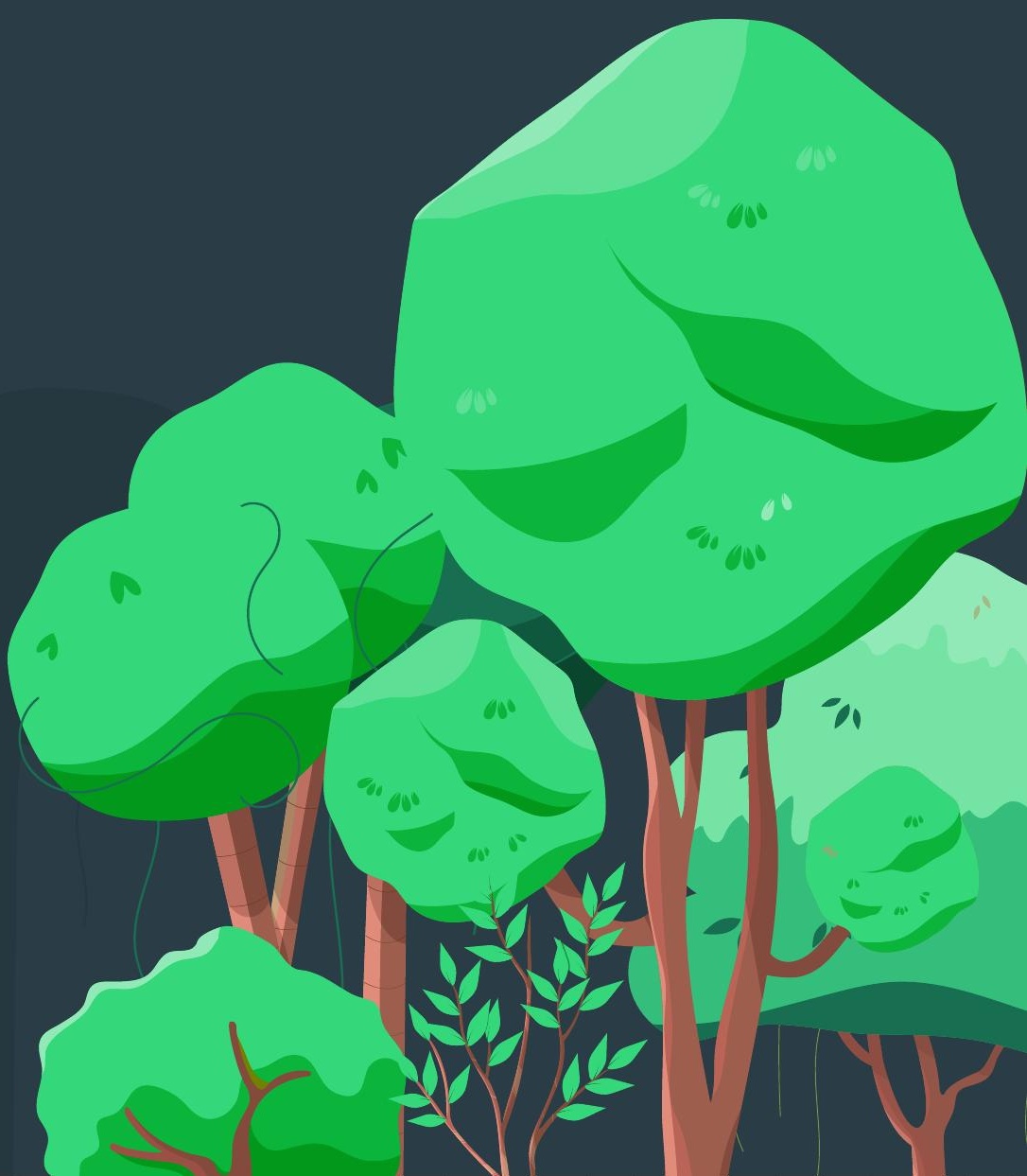


Gender inequality is among the most pervasive forms of discrimination in the world. It affects all aspects of life, from education and income, to rights, resources and services. When people of any gender are constrained from their full potential, it represents a loss for entire societies, impacting safety, wellbeing, progress and growth. ${ }^{3}$

\section{Gender mainstreaming}

Gender mainstreaming is the process of ensuring

that the concerns and experiences of all genders, including women, men, girls and boys, are addressed in the design, implementation, monitoring and evaluation of policies and programmes, at all levels and in all spheres. $^{8}$

Gender mainstreaming is a globally agreed strategy to identify gender inequalities and advance actions toward gender equality as a human right. ${ }^{8}$ Importantly, gender mainstreaming requires that women and men are viewed and positioned as equal stakeholders, actors and beneficiaries, including in sustainable development. This serves the interests of all women and men in its long-term purpose of eradicating inequities, transforming discriminatory laws and practice, and achieving a higher level of well-being for all. ${ }^{6}$

\section{GENDER MAINSTREAMING ACROSS POLICY/PROGRAMME CYCLES}

Measures need to be put in place to promote and integrate gender across all policy and programme cycles. These activities must include all actors and stakeholders to ensure progress toward gender equality. ${ }^{9}$

The following graphic identifies specific actions that can be undertaken at different stages of the policy/programme cycle.

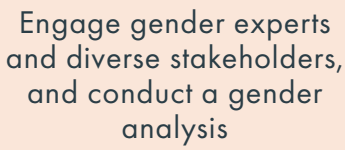

Engage gender experts and diverse stakeholders, and conduct a gender analysis

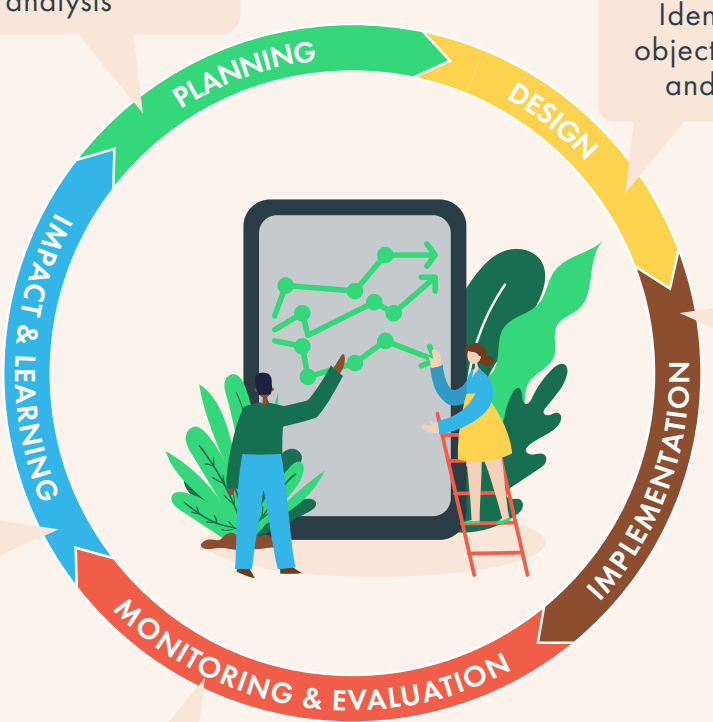
jectives, budget, and indicators

Assess outcomes and share knowledge

$$
\begin{gathered}
\text { Generate qualitative } \\
\text { and quantitative } \\
\text { gender data and carry } \\
\text { out reporting }
\end{gathered}
$$

Implement gender-responsive activities and build capacity 


\section{9) Gender analysis}

A gender analysis is needed to understand the formal (e.g., policies, programmes) and informal (e.g., norms, belief systems, customs) that shape opportunities and constraints as well as the different perspectives, interests and needs of the various stakeholders across the communities and socio-economic groups. This includes, for example, male and female farmers, traders, educators, health workers, formal and informal organised groups, Indigenous peoples, youth, and elderly people, amongst others. ${ }^{10}$

Gender analysis involves a critical examination of differences in gender roles, activities, needs, opportunities, and rights in a given context. Such an analysis is the basis of gender mainstreaming efforts and the development of interventions that address gender inequalities and meet the different needs of all people. ${ }^{9}$

\section{KEEP IN MIND}

A rigorous gender analysis will:

- Help to visualise the main areas where gender inequality exists in a specific context by examining the economic, social and legal aspects that contribute to skewed power dynamics between women, men, girls and boys.

- Provide the necessary data and information as a starting point to mainstream gender into policies, programmes and projects.

- Inform the development of interventions that address gender inequalities and meet the different needs of all people.?

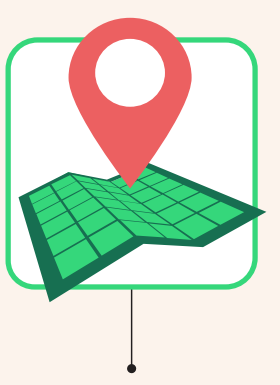

\section{Who does what?}

Tasks and responsibilities of men and women (adults, children, elders), and where and when these activities take place.

\section{What is the context?}

The demographic, legal, social and economic context, and social and cultural norms related to gender equality that shape behaviours of stakeholders and gender relations in the country/sector/geography.
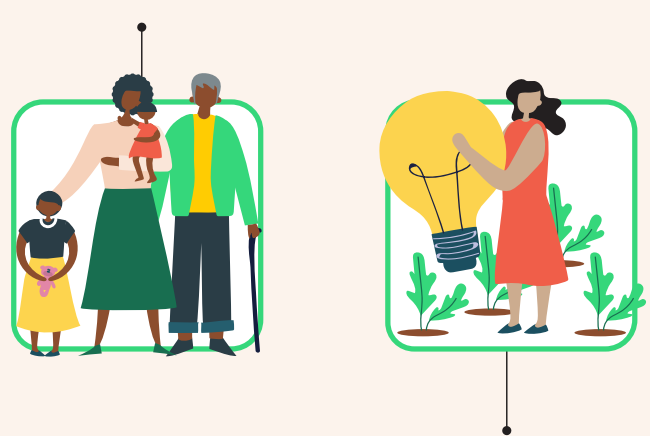

\section{Who has what?}

The resources and services that women and men from different social groups (e.g. based on age, socio-economic status, etc.), use, access, and control in households, communities, and public and private sectors.

\section{Who decides?}

How and to what extent women and men from different social groups, participate in decision making in households, communities, and the public and private sectors.

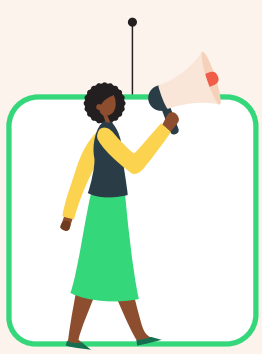

\section{Who benefits?}

The opportunities and entry points to ensure equal participation and benefits from the intervention for women and men of different social groups. 


\section{Stakeholder analysis}

Who is responsible for mainstreaming gender? Everyone!

Specific roles may include:

\section{- Government representatives and decision-makers:} Should build political will and interest to mainstream gender, creating enabling conditions and supporting integration through the specific allocation of budget.

- Programme managers and developers: Should adhere to, and advance, mandated gender strategies and tools for building evidence and understanding on gender dynamics across the cycle from project proposals to implementation, and knowledge sharing with all stakeholders.

- Community leaders and groups: Should share knowledge and build capacity across stakeholders and groups - including women and women's rights organisations - to encourage understanding and diverse participation in decision making on relevant issues.

- Gender specialists and advocates: Should provide expert knowledge and information on gender differentiated issues and dynamics to support all other stakeholders in implementing a gender-responsive approach throughout processes and initiatives. ${ }^{9}$

Intersectionality is key: it is important to recognise how factors such as gender, age, language, indigeneity, etc., contribute to a person's roles, priorities and capacity, including the capacity to participate in stakeholder engagement workshops. Applying an intersectional lens will help determine which groups should be especially considered when inviting stakeholders to the table. For example, women living in urban locations may not be well placed to represent rural women's interests; and wealthy women may not represent the needs and priorities of poorer women. ${ }^{6}$

Beyond women and girls, it is also important to meaningfully consider how other marginalised communities may be vulnerable, beneficiaries, stakeholders, and/or agents of change. ${ }^{10}$

\section{KEEP IN MIND: WOMEN AND} GIRLS AS AGENTS OF CHANGE

Within policies and programmes, women and girls are often described as vulnerable, as beneficiaries, as stakeholders, and/or as agents of change.

- While the unique vulnerabilities of men, women, boys and girls should be considered, relegating women and girls to simply a vulnerable group ignores the tremendous energy and agency that women and girls contribute to development, sustainability and restoration work. ${ }^{10}$

- Women are often included as beneficiaries within policies and programmes. Viewing a group as beneficiaries without also including them as participatory stakeholders has the potential to miss opportunities that enhance gender equality, or worse, perpetuate gender inequalities."

- Some policies and programmes recognize women as stakeholders when women community members, women natural resource managers, women's organisations and women from other relevant stakeholder groups are incorporated throughout the programme/policy cycle.?

- Policies and programmes should recognize and value the experience, abilities and leadership potential of women and include them as agents of change.

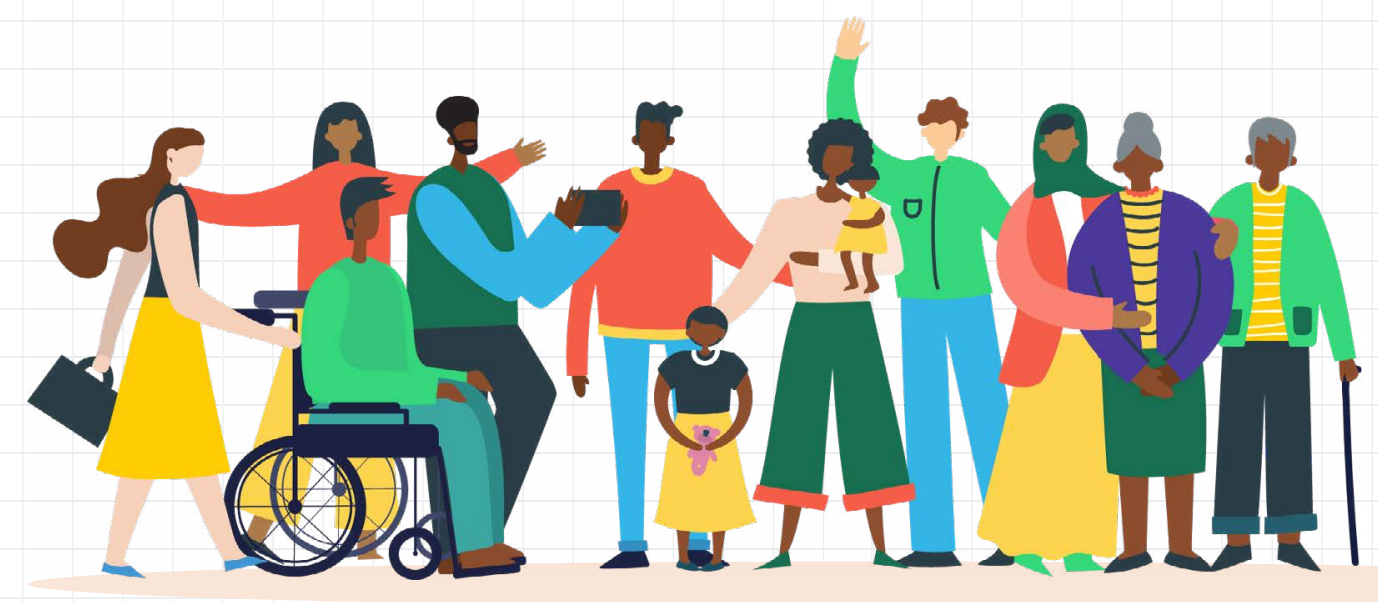




\section{Enabling conditions for mainstreaming gender}

Creating an enabling environment for gender equality that ensures that the rights of all genders are taken into account is necessary for sustainable development and advancing progress on restoration. ${ }^{3}$

An enabling environment creates conditions which ensure sustainable and equitable development across sectors, including restoration initiatives, while ensuring the rights and assets of all stakeholders (e.g. public and private sector organisations, as well as individual women, men, youth and their communities) are taken into account.

By means of sound policies, legal frameworks as well as financing and investment structures, conditions are created which support gender mainstreaming comprehensively across systems, institutions, levels and sectors. ${ }^{10}$

\section{KEEP IN MIND}

An enabling environment includes adequate

institutional arrangements as well as the regulation and enforcement of policies. ${ }^{8}$

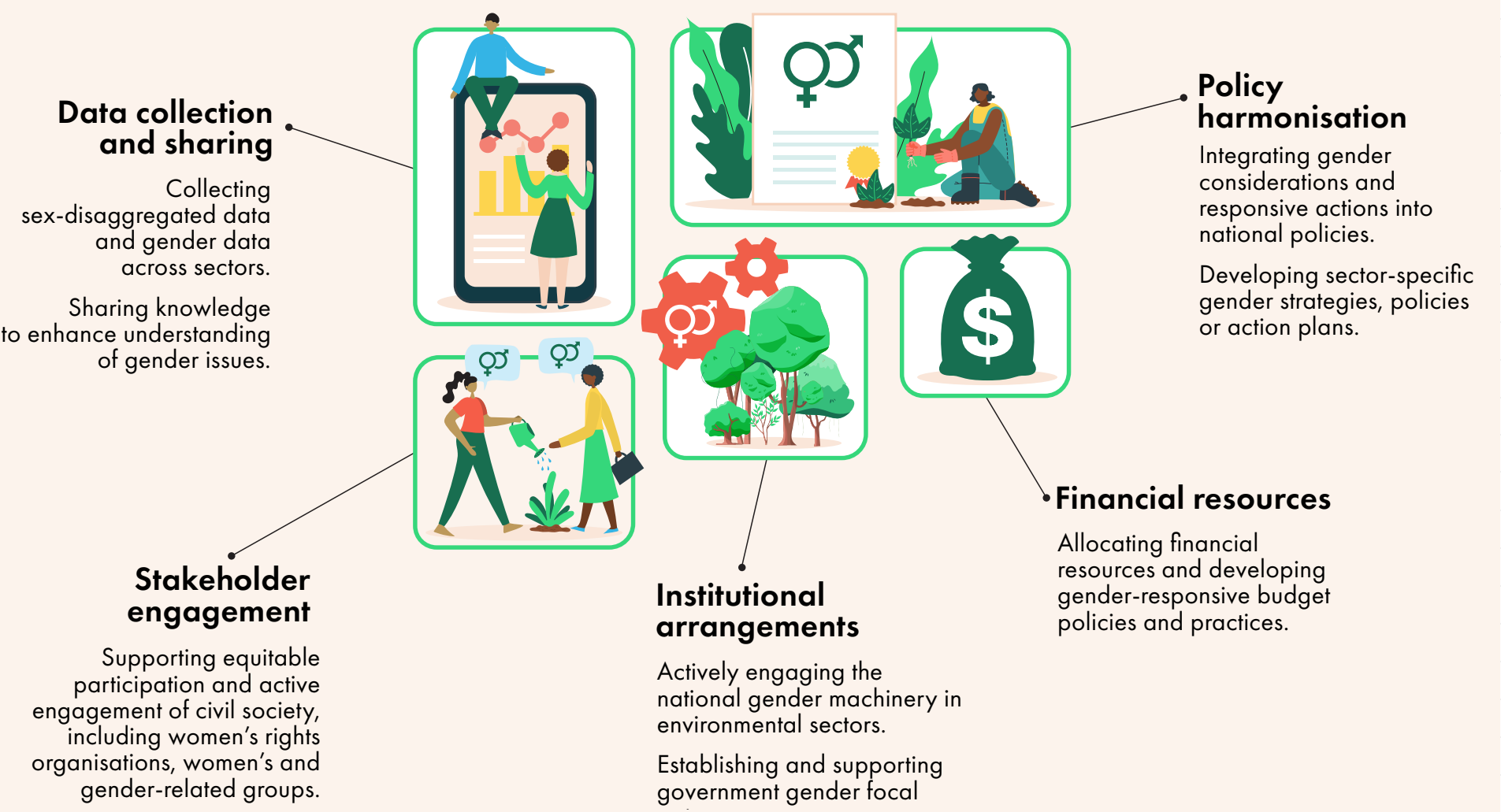




\section{Women's economic empowerment}

A woman is economically empowered when she has the power to make and act on economic decisions, to control resources and profits, and to benefit from economic activities. This requires the skills and resources to compete in markets, as well as fair and equal access to economic institutions. ${ }^{12}$

To support women's economic empowerment, organisations must address the underlying factors that contribute to it: individual and community resources, as well as norms and institutions.

Restoration initiatives can support women's economic empowerment when they provide them with fair compensation for their efforts and equitably distribute restoration benefits. Economic empowerment can be instrumental in shaping final outcomes (e.g., to help eradicate poverty or build vibrant communities) and can be a valuable outcome in itself..$^{13}$

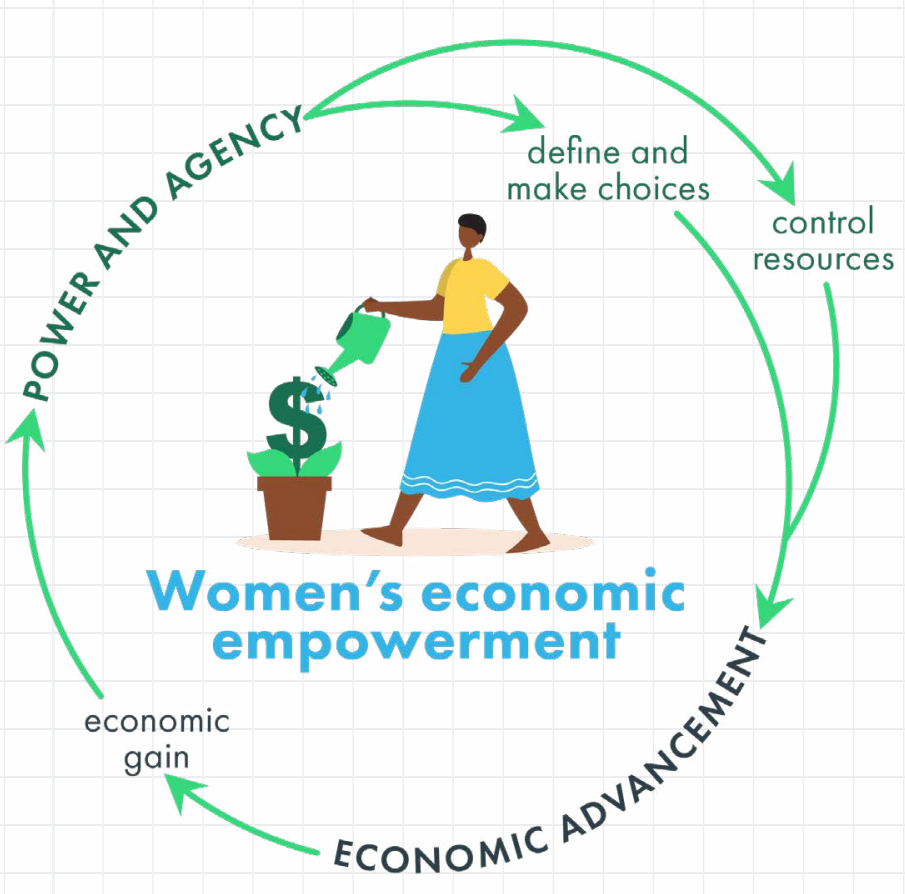




\section{Towards gender equality}

Making progress towards gender equality in policies, institutions, programmes and projects, and more generally across social, economic and political arenas, requires approaches that intentionally challenge inequalities. ${ }^{14}$ The 'gender equality continuum' shows a range of approaches that are increasingly transformative in terms of promoting gender equality (as illustrated below).

Gender-blind approaches are often constructed based on the principle of being "fair" by treating everyone the same. However, in reality it can mean that there is not equal participation and distribution of benefits.

Gender-sensitive approaches indicate gender awareness, although often no remedial action is developed.
Gender-responsive approaches intentionally target and benefit women, men, girls, and boys based on their specific needs to achieve certain policy or programme goals. This makes it easier for people to actively participate and contribute to solutions by accommodating gender roles and responsibilities.

Gender-transformative approaches seeks to address causes of gender inequality and includes ways to change harmful gender norms and power relations.

The end goal is meaningful gender equality, where structures are in place to ensure that everyone has equal opportunity and access and social, economic, and legal barriers are effectively erased.

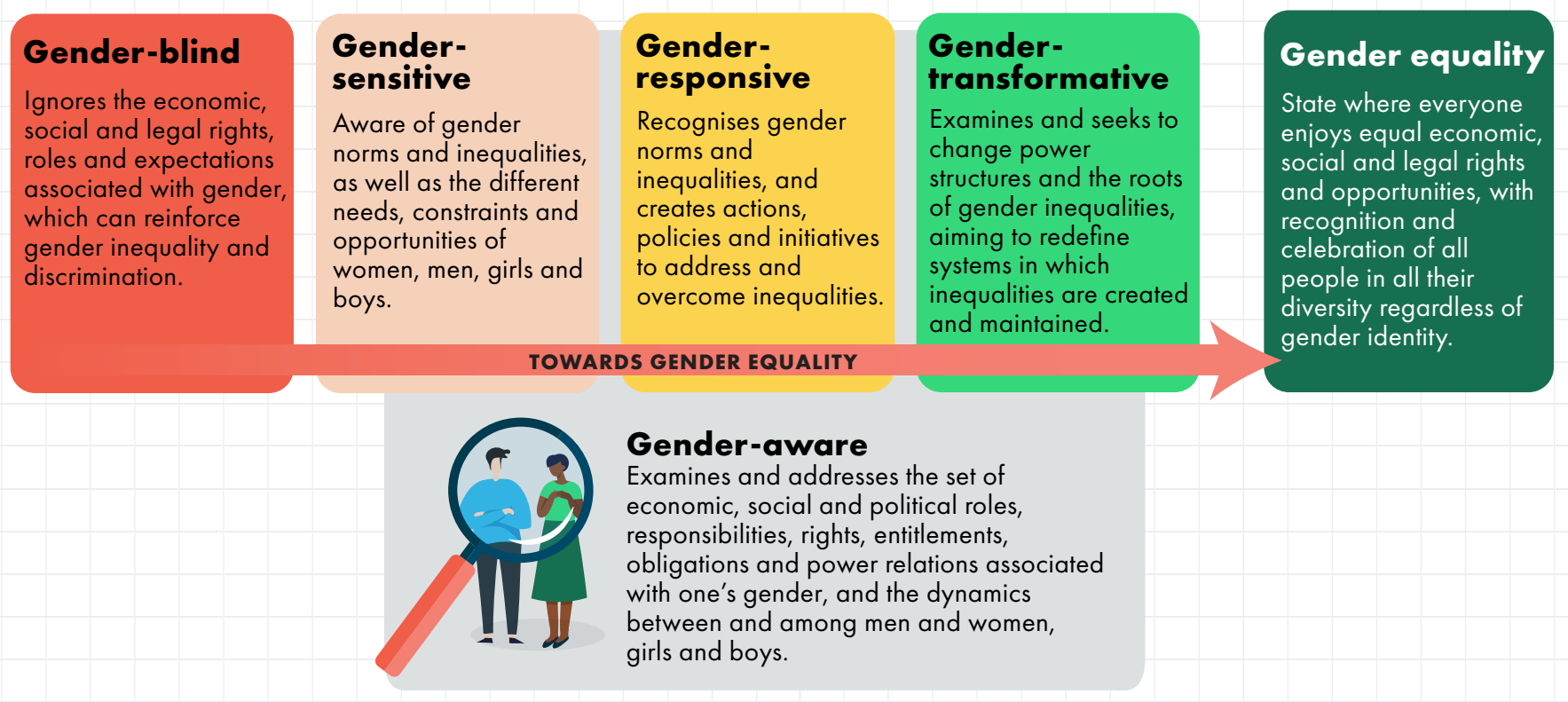




\section{Gender equity and equality frameworks}

There are many approaches that can be taken when planning, developing or assessing a gender-responsive initiative (programme/project/policy). Several frameworks offer different types of guidance to this process. ${ }^{15}$

A For example, the Social Equity Framework focuses on three dimensions of gender equity that the initiative may try to affect. ${ }^{16}$

B The Reach, Benefit, Empower Framework focuses instead on how the initiative is designed to effect change i.e., does it focus merely on reaching women through targeting them in interventions; is it explicitly designed to ensure that they actually benefit from the initiative; or does it actually include strategies to support their empowerment? ${ }^{17}$

C Developed specifically for the intersection of gender and FLR, the Safeguards, Benefits and Opportunities framework focuses on key gender equality entry points within FLR efforts. ${ }^{16}$

These frameworks overlap in considering the ways in which environmental and FLR programming may impact or be impacted by social aspects.

A social equity framework draws attention to three interrelated dimensions of equity that an initiative may explicitly try to affect:

- Recognition of women (or marginalised groups) as legitimate stakeholders, in this case in FLR

- Representation: equitable participation, decision making, voice and influence in FLR processes

- Equitable distribution of costs and benefits of FLR processes

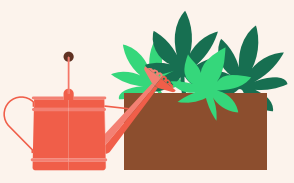

DISTRIBUTION

Costs (e.g., labour), benefits (e.g., income, capacities), access to resources, tenure

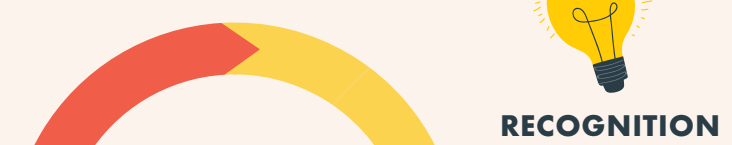

Knowledge, roles, responsibilities, valuation, priorities
The Reach, Benefit, Empower Framework can offer useful guidance for developing and assessing genderresponsive policies and programmes.

\section{REACH}

Include women in programme activities: Invite diverse representation and reduce barriers to participation

\section{BENEFIT}

Increase women's wellbeing (e.g., food security, income, health): Design projects to consider and respond to genderdifferentiated needs, preferences and constraints for women to benefit

\section{EMPOWER}

Strengthen the ability of women to make strategic life choices and to put those choices into action: Enhance women's decision making power in households and communities, addressing key areas of disempowerment 
This framework draws attention to three interrelated dimensions of equity that an initiative may explicitly try to affect:
In case of displacement of land or livelihoods, fair and legitimate compensation must be offered to all those affected.

There needs to be an adequate, accessible and effective grievance system.

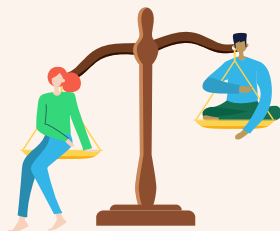

SAFEGUARDS

Free and prior informed consent; fair and

legitimate compensation; accessible and effective grievance system

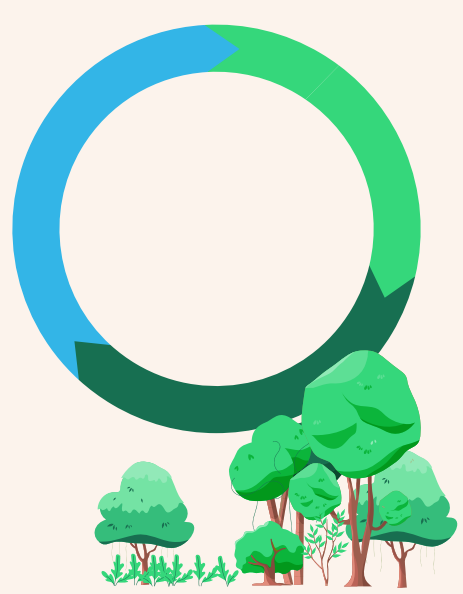

RESTORATION BENEFITS

Cash transfers, jobs, secure tenure, income earning opportunities, improved ecosystem services

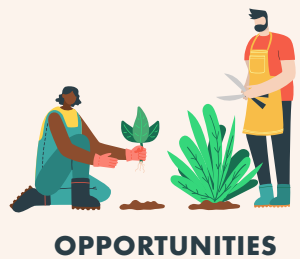

Reflect priorities, interests and knowledge of women and men; recognise and compensate women's and men's efforts; restoration benefits must be equitably distributed; both women and men must have an equal say in decisions related to FLR

\section{Global, national and regional pledges such as the \\ Bonn Challenge reflect the intention to restore large areas of degraded and deforested lands.}

However, these areas are claimed, used or accessed, formally and informally, currently or in the future. 


\section{Human rights}

Every individual is entitled to

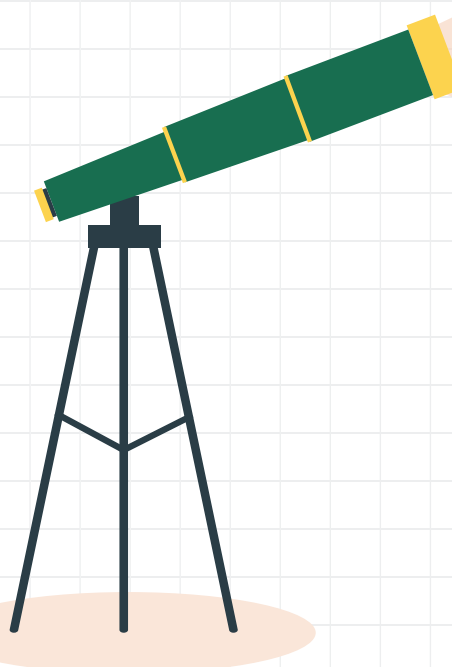
the same rights, responsibilities and opportunities, and they should not be discriminated based on their gender.

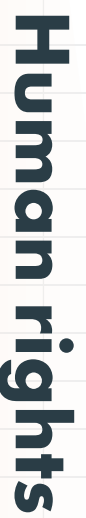

- All human beings are rights holders. The individuals and groups responsible for upholding and enabling the realisation of rights are duty bearers. Duty bearer responsibilities are typically categorised as respecting, protecting and fulfilling rights. ${ }^{18}$

- Empowerment and gender equality are critical aspects for the realisation of human rights for all women and men.

- A rights-based approach redefines development, transforming it from an act of charity to a legal obligation. The approach argues that the development process must be based on human rights principles - putting people and under-represented groups at the centre of development efforts. It also argues that development should build capacity of those involved and create the best environment for people to realise their rights. ${ }^{19}$

- Human rights include individual and collective rights. Human rights are inherent to individuals, we are born with the right to life, security and a healthy environment and no-one can take these rights away, regardless of sex, ethnicity, political ideas and social origin. ${ }^{18}$ In addition to these individual rights, Indigenous peoples possess collective rights which are indispensable for their existence, well-being and integral development as peoples. These collective rights include the right to self-governance and self-determination. ${ }^{20}$

\section{KEEP IN MIND}

A rights-based approach positions people, including those historically marginalised, as active agents in processes affecting their lives and ensures accountability of those with responsibilities and obligations to others. $^{18}$ 


\section{- A human rights approach to conservation}

Conservation can help realise substantive human rights, such as those related to health, culture and food. Likewise, the realisation of human rights can create an enabling environment for achieving conservation objectives. ${ }^{19}$

Key elements can include:

- Identifying all relevant rights, claims and obligations, including customary and collective rights.

- Using rights, norms, standards and principles to guide policy, programming and implementation.

- Analysing and monitoring processes and outcomes against rightsbased criteria.

- Engaging with the rights implications of conservation practice as a matter of obligation.

- Supporting efforts to address the underlying causes of rights violations, including by changing inequitable power relations.

- Building the capacity of both rights holders and duty bearers to claim their rights and meet their respective responsibilities.

- Taking all available measures to respect rights in all cases and supporting their protection and further fulfilment wherever possible, particularly for the most vulnerable.

- Supporting efforts to provide access to justice and redress for violations. ${ }^{23}$

\section{KEEP IN MIND}

A human rights-based approach can be carried out at multiple scales, through various legal instruments, policies, programming approaches, methods and tools. ${ }^{19}$

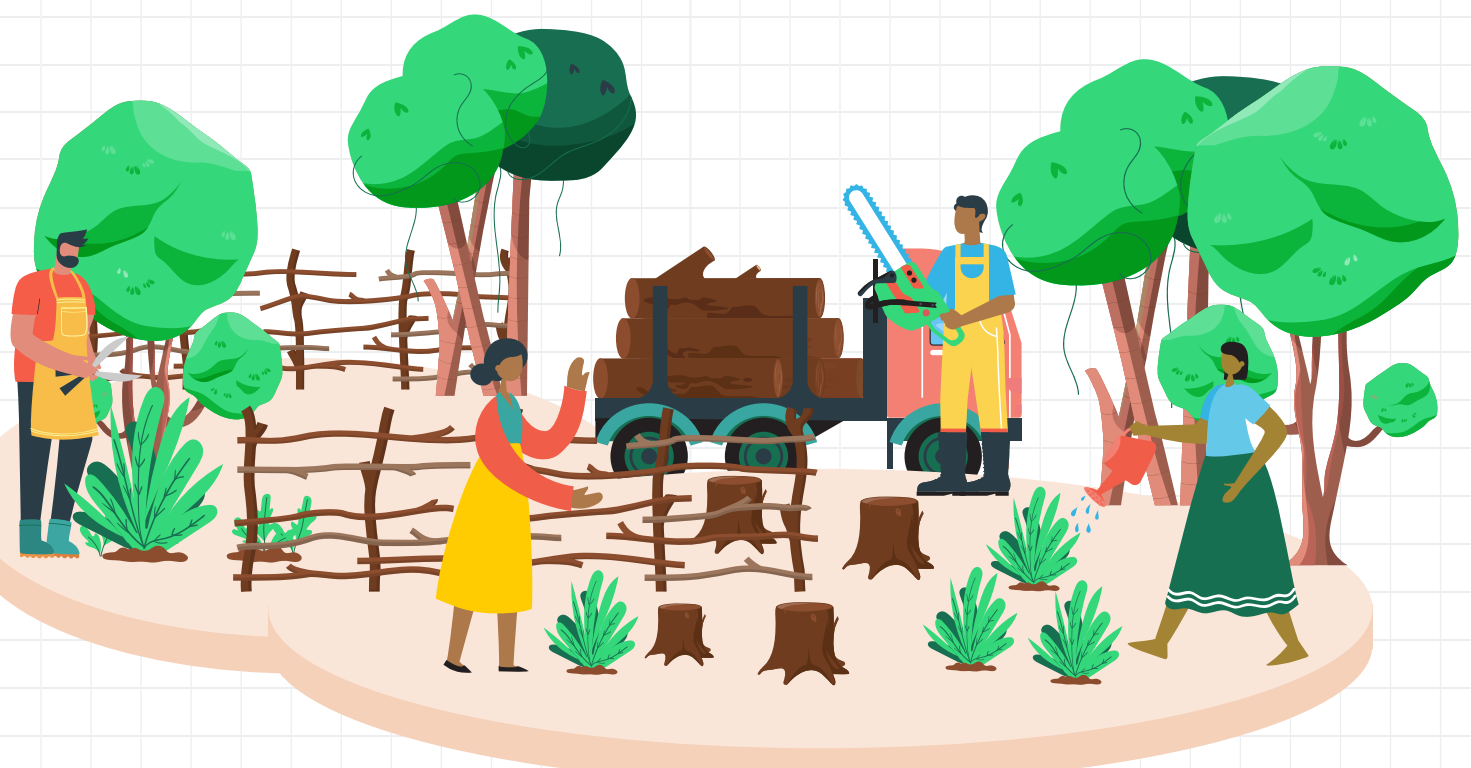




\section{A human rights approach to restoration}

Rights-based restoration is designed, governed and implemented with communities who best understand the local reality. Recognising that ecological and social well-being are connected, it increases biodiversity and environmental health while securing local community rights. ${ }^{21}$

Restoration initiatives can be categorised according to the ways they approach rights and sustainability:

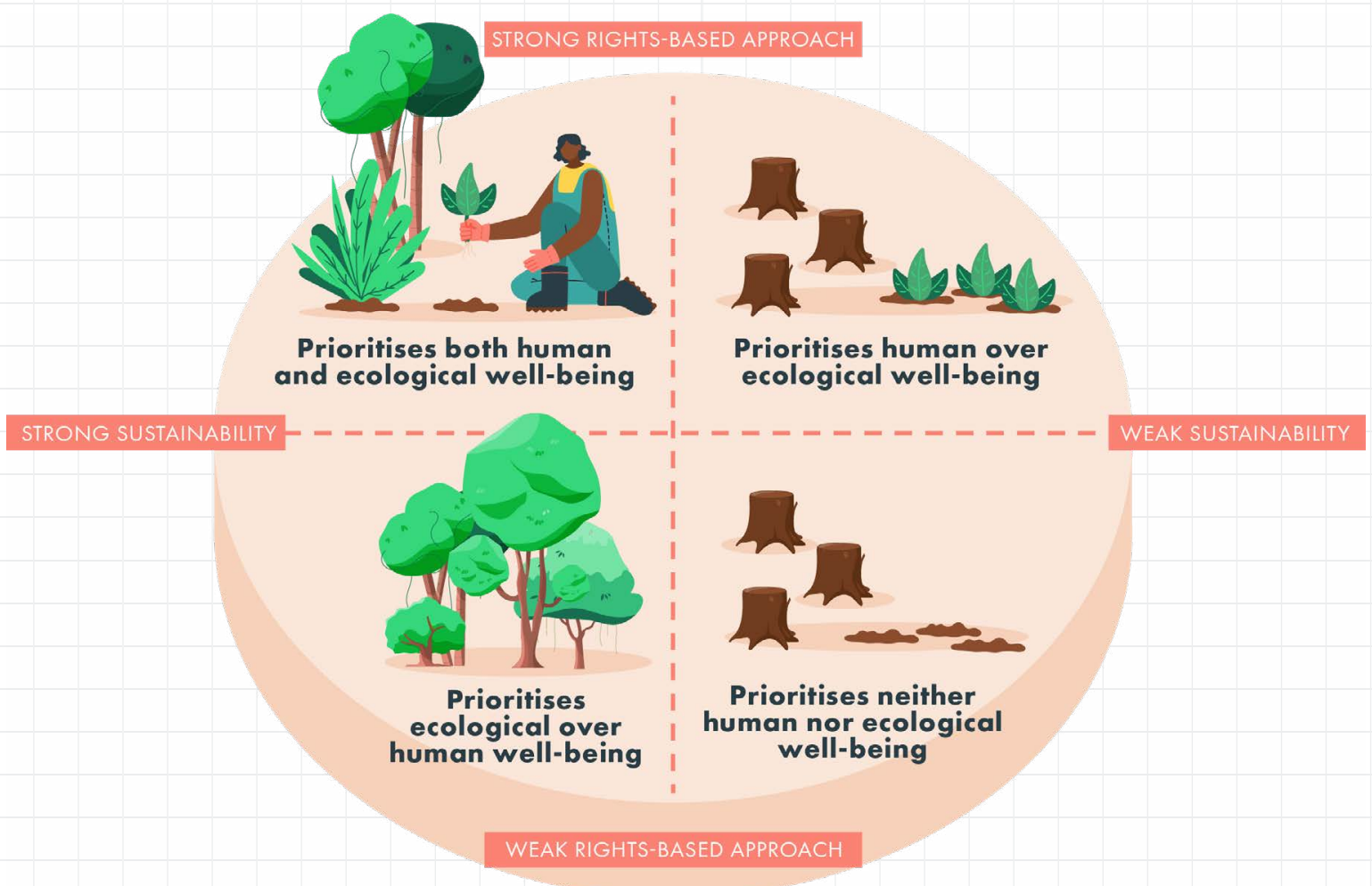

\section{CASE STUDY: GHANA}

A case study that analyses restoration initiatives in Ghana provides the following recommendations:

1 Policies and funding bodies should prioritise rights-based approaches to restoration by distinguishing between different types of forest landscape projects and redirecting support to rights-based restoration models.

$\checkmark$ Restoration projects should be led by national experts in community forestry and forest governance, in partnership with civil society and communities.

Restoration funds should be established within countries from commodity taxes and distributed to rights-based restoration initiatives through local authorities and civil society organisation platforms. ${ }^{22}$ 


\section{PART THREE}

Gender equality and
social inclusion in the international agenda

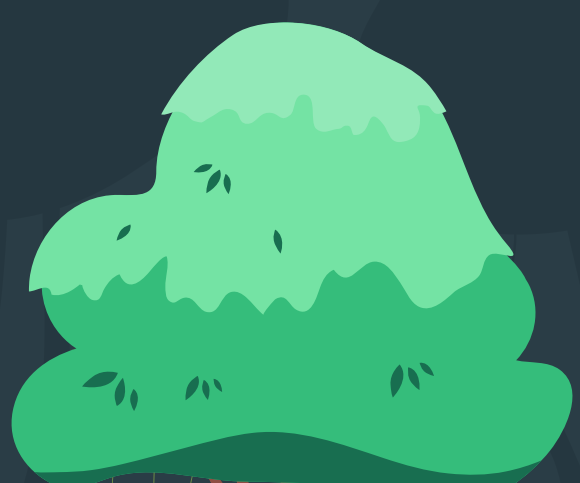

$n, M M \cap A$

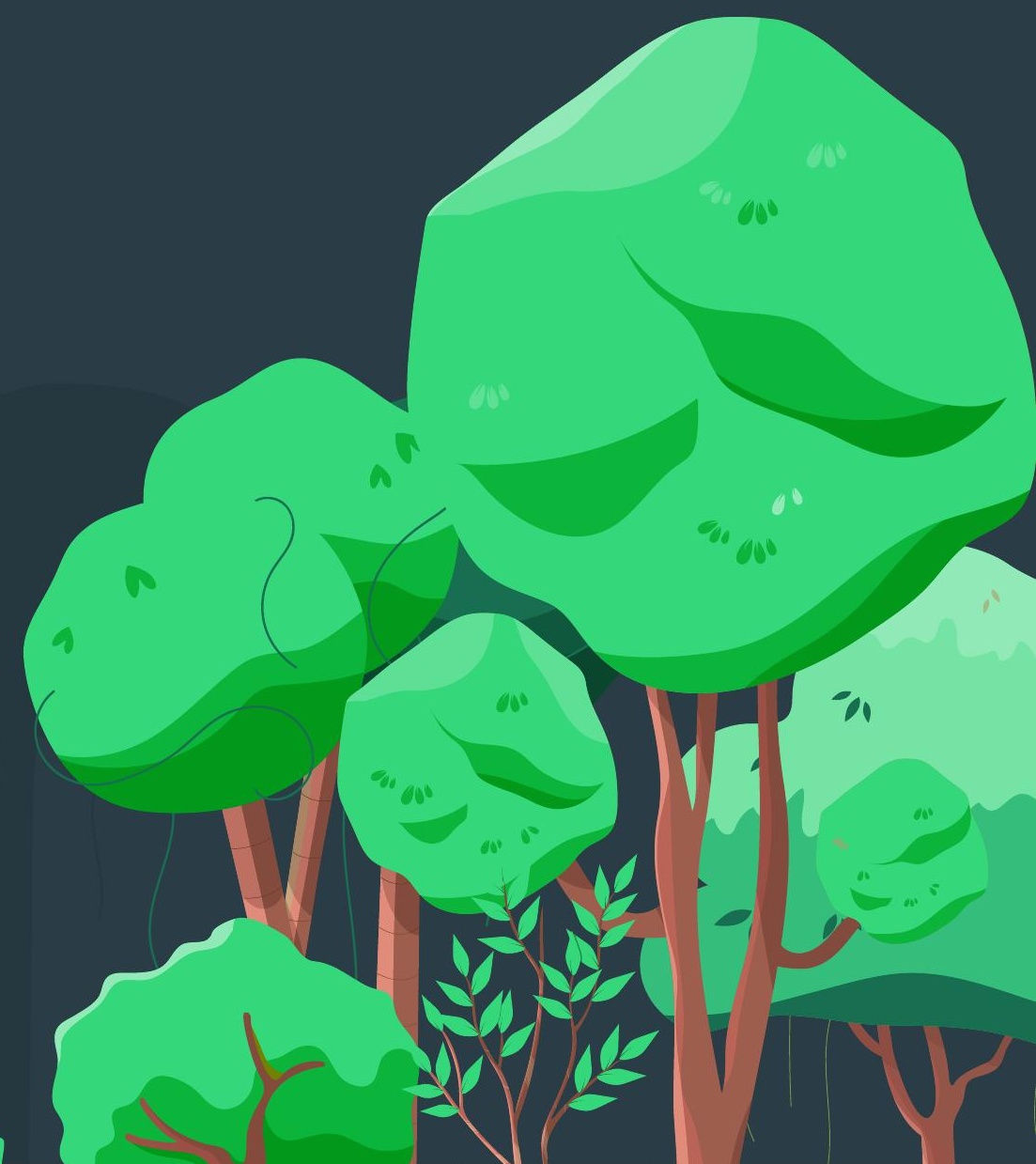


Gender equality and social inclusion are priorities across international, regional, national and sub-national levels in various policies and agendas. The international community has many agreed upon frameworks relevant to gender equality. Additionally, gender equality is increasingly recognised as a priority across sectors, such as in climate change and FLR agendas. ${ }^{23}$

Three relevant examples of gender equality frameworks and agendas are:
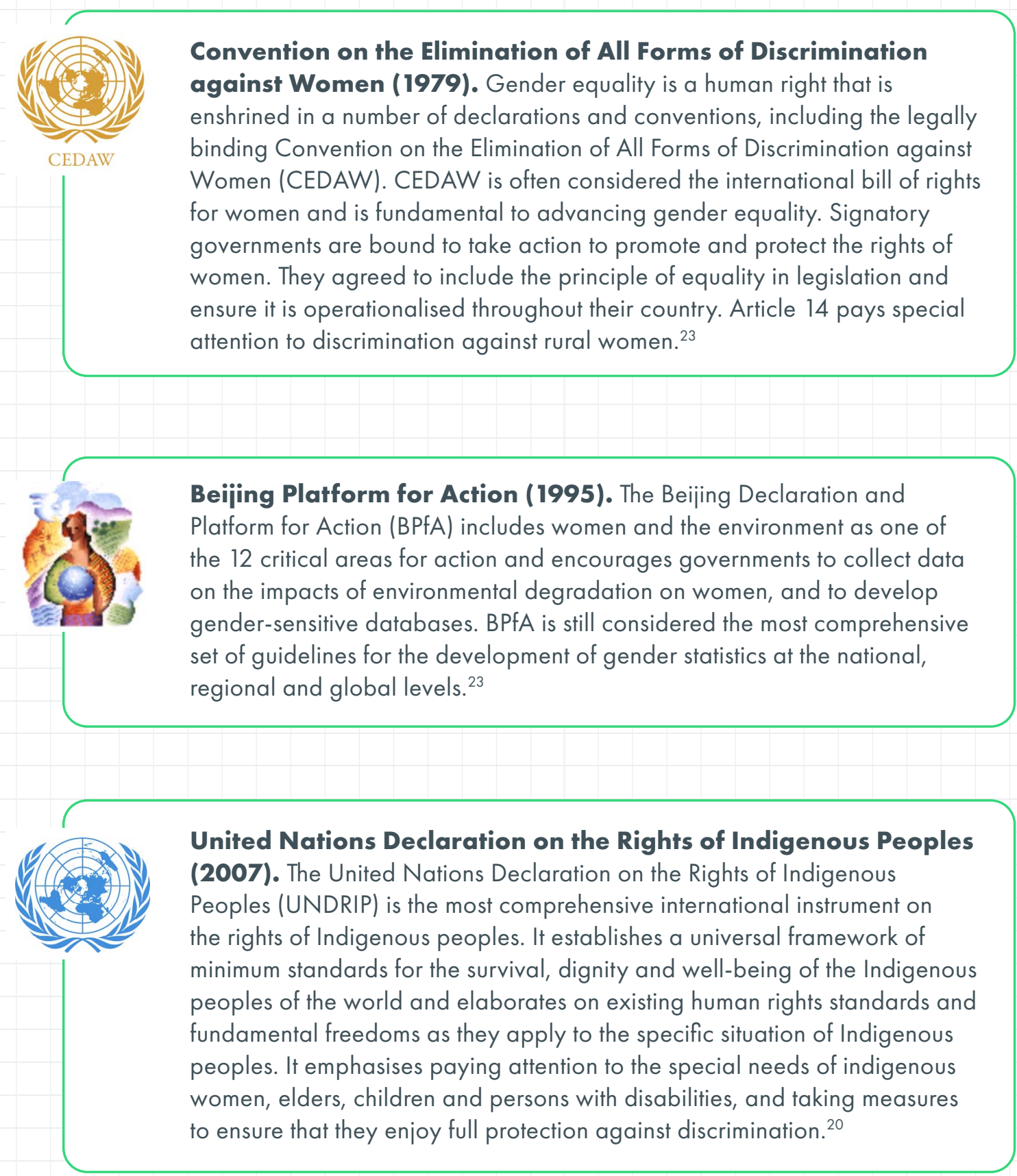
1. Canadian Institutes of Health Research. 2020. What is gender? What is sex? Government of Canada. Viewed 21 October 2021, https://cihr-irsc.gc.ca/e/48642.html.

2. WHO. 2021. Gender and health. World Health Organisation. Viewed 21 October 2021 https://www. who.int/health-topics/gender\#tab=tab_1.

3. Basnett BS, Elias M, Ihalainen M, Paez Valencia AM. 2017. Gender matters in Forest Landscape Restoration: A framework for design and evaluation. Center for International Forestry Research (CIFOR).

4. Ferrant, G., Pesando, L.M., Nowacka, K. 2014. Unpaid Care Work: The missing link in the analysis of gender gaps in labour outcomes. OECD Development Centre. Available at: https://www.oecd.org/dev/developmentgender/Unpaid_care_work.pdf

5. Robert Wood Johnson Foundation (RWJF). 2017. Visualizing health equity: One size does not fit all infographic. Robert Wood Johnson Foundation. Viewed 21 October 2021, https://www.rwif.org/en/library/ infographics/visualizing-health-equity.html.

6. Colfer CJP, Basnett BS, Ihalainen M. 2018. Making sense of 'intersectionality': A manual for lovers of people and forests. Occasional Paper 184. Bogor, Indonesia: CIFOR.

7. Simpson J. 2009. Everyone Belongs: A toolkit for applying intersectionality. 1st Edition. CRIAW-ICREF.

8. UN Women. n.d. Gender mainstreaming. Viewed 21 October, 2021 < https://www.unwomen.org/ en/how-we-work/un-system-coordination/gendermainstreaming>.

9. UNIDO. n.d. UNIDO guide to gender analysis and gender mainstreaming in the project cycle. United Nations Industrial Development Organisation.

10. UNDP. 2015. Guidance Note Gender Sensitive REDD+. United Nations Development Programme. Available at: https://www.undp.org/publications/guidance-notegender-sensitive-redd-0

11. IUCN, 2018. Gender-responsive Restoration Guidelines. International Union for the Conservation of Nature. Available at: https://portals.iucn.org/library/sites/ library/files/documents/2017-009.pdf

12. Golla AM, Malhotra A, Nanda P, Mehra R. 2011. Understanding and measuring women's economic empowerment: Definition, framework and indicators. International Center for Research on Women (ICRW).

13. USAID. Women's Economic Empowerment: Advancing Women's Economic Empowerment. Available at: https://www.usaid.gov/what-we-do/gender-equalityand-womens-empowerment/womens-economicempowerment.
14. Nelson S, Hill C. 2019. Gender in adaptation planning for the agriculture sectors: Guide for trainers. FAO and UNDP. Rome.

15. Quisumbing A, Meinzen-Dick R, Malapit H. 2017. Reach, benefit, empower: Indicators for measuring impacts of projects and policies towards gender equality. Gender, Agriculture and Assets Project (GAAP2), IFPRI. [SlideShare] Viewed 21 October 2021, < https://www. slideshare.net/IFPRI-PIM/reach-benefit-empowerindicators-for-measuring-impacts-of-programs-andpolicy-towards-gender-equality>.

16. Elias, M. 2020. Integrating gender in agriculture and forestry in the context of climate change. Available at: https://fao.adobeconnect.com/_a1026619000/ pv6uyg7ihy $4 \mathrm{r} /$ ? proto=true

17. Theis, S. \& Meinzen-Dick, R. 2016. Reach, benefit, or empower: clarifying gender strategies of development projects. International Food Policy Research Institute. Available at: https://www.ifpri.org/blog/reach-benefitor-empower-clarifying-gender-strategies-developmentprojects

18. UNFPA. 2010. A human rights-based approach to programming: Practical implementation manual and training materials. United Nations Population Fund.

19. Campese J, Sunderland T, Greiber T, Oviedo G. (eds.) 2009. Rights-based approaches: Exploring issues and opportunities for conservation. CIFOR and IUCN. Bogor, Indonesia.

20. UNDRIP. 2007. United Nations declaration on the rights of Indigenous peoples. United Nations.

21. Springer, J. 2016. IUCN's Rights-Based Approach: A Systemization of the Union's Policy Instruments, Standards and Guidelines. International Union for the Conservation of Nature. Available at: https://www.iucn. org/sites/dev/files/content/documents/iucn_rba_ systematization_compiled.pdf

22. Bissell C. 2020. Restoring more than forests: How rightsbased forest restoration can empower communities, recover biodiversity, and tackle the climate crisis. Fern.

23. Women4Biodiversity. 2020. International genderenvironment policy framework. Viewed 21 October 2021 https://www.women4biodiversity.org/internationalgender-environment-policy-framework/. 

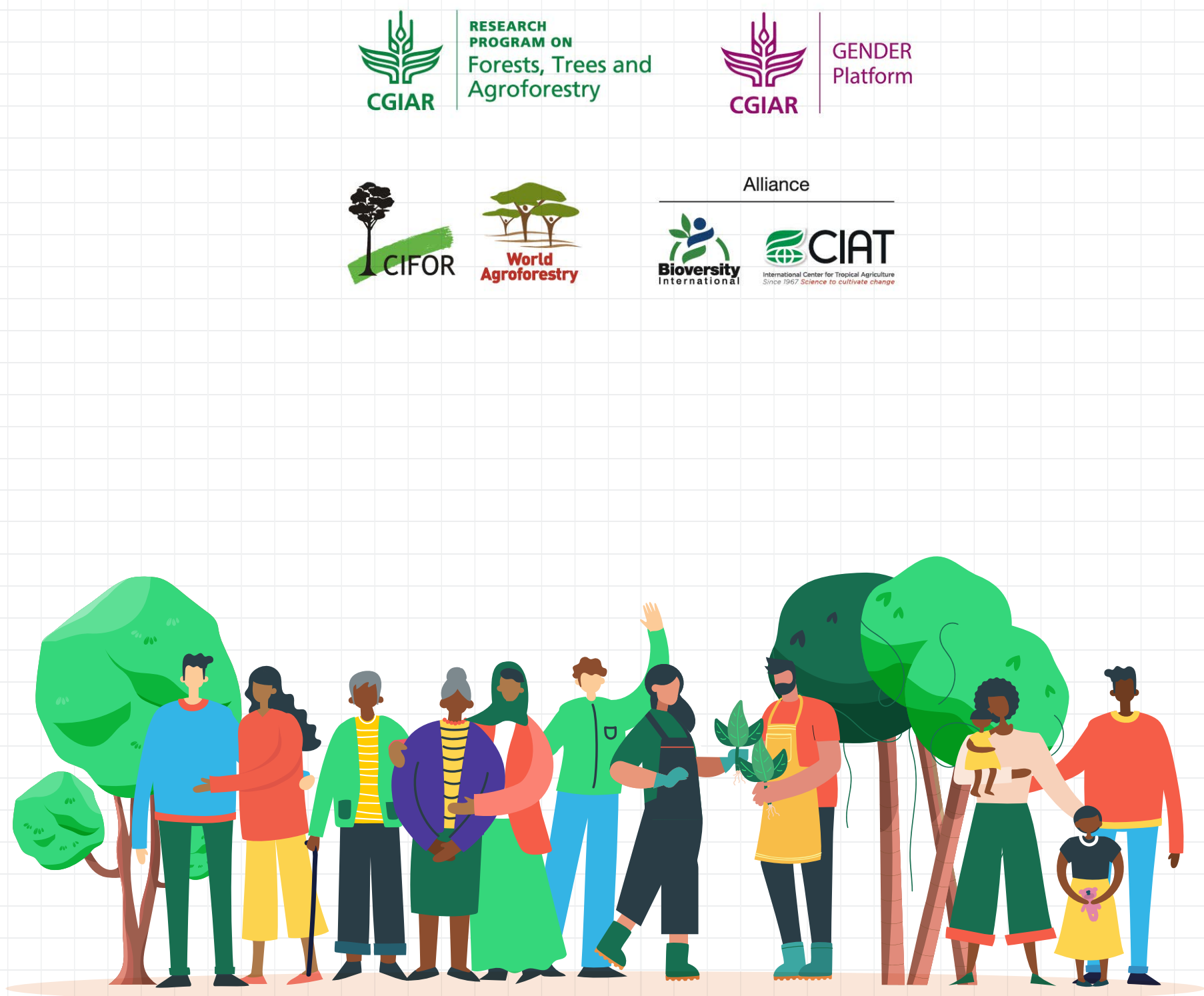